\title{
Adiponectin Multimeric Forms but not Total Adiponectin Levels are Associated with Myocardial Infarction in Non-Diabetic Men
}

\author{
Andrea Baessler ${ }^{1}$, Susanne Schlossbauer ${ }^{1}$, Klaus Stark ${ }^{1}$, Christina Strack ${ }^{1}$, Günter Riegger ${ }^{1}$, \\ Heribert Schunkert ${ }^{2}$, Christian Hengstenberg ${ }^{1}$, and Marcus Fischer ${ }^{1}$ \\ ${ }^{1}$ Clinic for Internal Medicine II, University of Regensburg, Germany \\ ${ }^{2}$ Clinic for Internal Medicine II, University of Schleswig-Holstein, Campus Lübeck, Germany
}

\begin{abstract}
Aim: Multimer complex formation of adiponectin is recognized as an important mechanism modulating the biological functions of this adipokine, but the role of adiponectin isoforms in myocardial infarction (MI) is still unclear.

Methods: We quantified total adiponectin (TOTAL), high, middle, and low molecular weight adiponectin multimers (HMW, MMW, LMW) in a study of non-diabetic obese (BMI $\geq 30 \mathrm{~kg} / \mathrm{m}^{2}$ ) and normal-weight $\left(B M I \leq 25 \mathrm{~kg} / \mathrm{m}^{2}\right)$ male subjects with MI and healthy controls $(n=180)$. Subsequently, we designed a prospective nested-case-control study to investigate the association of the adiponectin multimers with fatal and non-fatal MI in $n=1236$ initially healthy non-diabetic men.

Results: Obesity was significantly related to lower levels of TOTAL, HMW, MMW, and LMW in subjects with and without MI $(p<0.01$, each). In contrast, MI was strongly related to MMW/ TOTAL $(p<0.0001)$, inversely to HMW/TOTAL $(p<0.0001)$, but not TOTAL or LMW levels. In particular, the median MMW/HMW ratios were markedly different in men with MI $(1.71$, interquartile range $(1.08-2.40))$ and without $(0.72(0.49-1.08), p<0.0001)$. In the prospective study, 56 incident fatal and non-fatal MI events occured. The MMW/HMW ratio was associated with fatal and non-fatal MI up to 5 years before the event. The ß-estimates for the relationship between MMW/HMW and incident MI decreased with increasing time to the event.

Conclusions: Whereas total adiponectin and all isoforms are related to obesity, total adiponectin and LMW levels are not associated with MI in non-diabetic men. In contrast, the MMW/HMW-ratio correlated with incident MI up to 5 years before the event. These data imply that measurement of adiponectin multimers adds significant value in assessing cardiovascular risk compared to total adiponectin alone.
\end{abstract}

J Atheroscler Thromb, 2011; 18:616-627.

Key words; adiponectin multimers, myocardial infarction, risk factors, prevention

\section{Introduction}

Substantial evidence demonstrates that hypoadiponectinemia is associated with insulin resistance and obesity, type 2 diabetes mellitus, and metabolic syndrome $^{1-4)}$. Besides these effects, adiponectin may also

Address for correspondence: Marcus Fischer, Clinic for Internal Medicine II, University of Regensburg, Franz- Josef-Strauss Allee 11, 93053 Regensburg, Germany

E-mail: marcus.fischer@klinik.uni-regensburg.de

Received: December 29, 2010

Accepted for publication: January 28, 2011 play important roles in protecting against coronary artery disease (CAD) because of additional anti-inflammatory, anti-apoptotic and anti-atherogenic properties $^{5-9)}$. Indeed, a number of studies have reported hypoadiponectinemia as an independent risk factor for the presence and/or severity of prevalent or incident $\mathrm{CAD}^{5,8,10-14)}$. However, others provided controversial, even opposite results challenging the accumulated cellular, animal, and human epidemiological data that supported adiponectin's role as a protective cardiovascular molecule ${ }^{4,15-21)}$. In fact, a recent meta-analysis of 7 prospective studies found no association between 
adiponectin and $\mathrm{CAD}^{22)}$. Thus, it has been speculated that the putative association between adiponectin and $\mathrm{CAD}$ events may be due to confounding by other factors, particularly sex effects, type 2 diabetes and dyslipidemia $\left.{ }^{19}, 20,22\right)$. Besides the known sexual dimorphism of adiponectin and the potential effect of hormonal fluctuations during the menstrual cycle on adiponectin levels ${ }^{23-25)}$, different stages of diabetes significantly influence adiponectin levels ${ }^{26)}$; however, prospective studies addressing the relationship between adiponectin and incident CAD events aimed at investigating homogeneous cohorts of patients with or without such major confounding factors are lacking.

Moreover, special attention should be paid to the analytical determination of this adipokine, present in the human circulation in predominantly three multimeric forms, i.e. low molecular weight trimeric form (LMW), mid-molecular hexameric weight form (MMW), and high-molecular-weight multimers $(\mathrm{HMW})^{27,28)}$. These isoforms have different biological activities, transduction modes, and exert distinct functions on its target tissues ${ }^{6,28,29)}$.

In fact, it has been observed that the HMW form is an active form, and its ratio with total adiponectin appears to be better correlated with insulin sensitivity and the metabolic trait cluster as well as $\mathrm{CAD}^{27,30-33) \text {. }}$ Based on these findings, the importance of the selective measurement of adiponectin multimers has been claimed $^{27,}$ 28, 34-36); however, for reasons of economy and complex, laborious procedures most studies have quantified total and HMW adiponectin, ignoring MMW and LMW isoform proportions. To our knowledge, no prospective study has evaluated the effect of all adiponectin isoforms on CAD endpoints, except one small cross-sectional study in octogenarians ${ }^{37)}$.

Here, we quantified total adiponectin and all adiponectin isoforms; first, in a cross-sectional exploratory study of obese and lean men with myocardial infarction (MI) and apparently healthy controls without evidence of CAD. Second, we conducted an independent prospective nested case-control study in initially healthy subjects to examine the association between adiponectin isoforms and the prospective risk for fatal and non-fatal MI. In both settings, with the atherosclerotic disease process being at different stages, we restricted the study participants to non-diabetic male subjects in order to reduce heterogeneity of the study populations and to reduce confounding by sex effects and diabetes.

\section{Methods}

\section{Study participants}

All of the study participants derived from the German MI family study. The background of these subjects has been described elsewhere ${ }^{38-40)}$. All subjects had been phenotyped by the same protocol: a standardized questionnaire was administered by specially trained telephone interviewers regarding medical and social history, medication, angina, and clinical events. All patients underwent a thorough physical examination, including a venipuncture to obtain a blood sample for cardiovascular risk factor assessment. Blood pressure was measured under standardized conditions. Additionally, all hospital records and all available records from the primary physician were obtained and critically revised. The Ethics Committee of the University of Regensburg approved the study protocol and all participants gave written informed consent. The study conforms with the Declaration of Helsinki.

\section{Cross-sectional exploratory study}

Using an automated, randomized selection procedure, 180 patients who fitted our prespecified selection criteria were selected from the German MI family study: as we focused on MI and to reduce the heterogeneity of the study population, we restricted the study participants to non-diabetic male subjects with and without MI (because different stages of diabetes influence adiponectin level ${ }^{26,41)}$ as well as the known sexual dimorphism of adiponectin, and homonal fluctuations during the menstrual cycle ${ }^{23-25)}$. Furthermore, only one subject from each family and only MI cases who had suffered their first MI were selected for the present study. Moreover, the delay between MI and the biological measurement was between 4 weeks and 1 year to reduce the heterogeneity of the blood samples.

We stratified the participants for obesity to investigate the relationship between MI and adiponectin levels in both normal and obese subjects. Thus, four different study groups were examined: normal-weight subjects (BMI $>18 \mathrm{~kg} / \mathrm{m}^{2}-<25 \mathrm{~kg} / \mathrm{m}^{2}$ ) without evidence of CAD (i.e. asymptomatic subjects with no history of angina or cardiac catheterizations, $n=45$ ), obese subjects (BMI $\geq 30 \mathrm{~kg} / \mathrm{m}^{2}$ ) without evidence of CAD $(n=45)$, normal-weight subjects who had recently suffered an MI $(n=45)$, and obese MI patients $(n=45)$. All individuals were matched for age $(5$-year intervals).

\section{Prospective nested case-control study}

Additionally, we conducted a prospective, nested 
case-control study in 1236 intially asymptomatic healthy siblings of $\mathrm{CAD}$ patients derived from the German MI family study cohort. Thus, these initially healthy subjects had a positive family history of premature MI. Analogously to the cross-sectional study, all subjects were of male gender, had no evidence of diabetes mellitus, and came from different families. During a mean follow-up of $8.0 \pm 0.6$ years, 56 of the initially asymptomatic siblings experienced an incident fatal or non-fatal MI. For each individual with such a confirmed event (referred to as "cases"), 2 "controls" were selected randomly from the 1180 siblings who remained free of any reported cardiovascular events and symptoms (such as chest discomfort) until the point of time when the case was diagnosed. Thus, 112 controls were matched for analysis time, age in decades, and BMI $\left( \pm 3 \mathrm{~kg} / \mathrm{m}^{2}\right)$. In follow-up investigations (at 2.5 years, 5 years, and after 8 years) clinical outcomes were recorded and a detailed history of current risk factors, medication, and discomfort was documented. For all possible events, clinical information was sought directly from the hospital or general practitioners' charts. All details of ECG, hospital admissions, enzymes, and treatment were collected. For all cases of MI and coronary death, hospital records were obtained and reviewed. MI was classified as confirmed if symptoms met the criteria of the World Health Organization and if the event was associated with abnormal levels of cardiac enzymes and diagnostic electrocardiographic changes. Diagnosis of death was confirmed with additional information from hospital records, autopsy reports, and family contact. Follow-up was achieved in $>95 \%,>85 \%$ and $>75 \%$ of the overall cohort at $2.5,5$, and 8 years, respectively.

\section{Definitions}

Obesity was defined as a BMI $\geq 30 \mathrm{~kg} / \mathrm{m}^{2}$, normal-weight was defined as a BMI between 18 and 25 $\mathrm{kg} / \mathrm{m}^{2}$. Type 2 diabetes was a positive history of diabetes, use of antidiabetic drugs or insulin, and/or a glycosylated hemoglobin level $\geq 6.5 \%$. The diagnosis of MI was validated through inspection of hospital charts. In subjects without MI, no evidence of CAD existed and all subjects were free of any symptoms compatible with CAD at inclusion in the study and at follow-up telephone interviews.

\section{Adiponectin measurements}

Adiponectin measurements were assessed and centralized with the technician blinded with respect to MI and obesity status in the exploratory study as well as to the case-control status in the prospective study. All blood samples were centrifuged immediately after venipuncture. Samples were stored at $-80^{\circ} \mathrm{C}$.

Serum total adiponectin and adiponectin isoforms were determined using the Adiponectin multimeric enzyme immunoassay (ALPCO Diagnostics, Salem, NH, USA). The kit operates on the principle of a sandwich format ELISA. The retest correlation and accuracy statistics between duplicate measurements (25\% of samples) obtained on different days with the samples randomly assigned to different analytical batches revealed excellent concordance (concordance correlation coefficient for total adiponectin, $0.995(0.992-0.998))$.

\section{Statistical Analysis}

Student's $t$-test was used to evaluate differences in the means and the chi-square test was used to compare proportions. As some adiponectin isoform traits and/or the isoform/total adiponectin ratios do not follow a multivariate normal distribution, all adiponectin parameters (as well as other non-normally distributed variables) were normalized using empirical normal quantile transformation for statistical analysis. This is an efficient transformation which has been proven to have better power than square-root and logarithm transformations, and allows direct comparisons with respect to the predictive capabilities of the different variables ${ }^{42)}$; however, continuous data were presented as medians with 25 th and 75 th percentiles in order to provide a better sense of the distribution of non-normally distributed variables.

Based on previous research we assumed a mean total $(\log )$ adiponectin of 1.80 and a standard deviation of 0.45 in controls. To detect a difference in (log)adiponectin levels of 0.2 between MI cases and controls, at least 161 subjects were required in the cross-sectional study to obtain $80 \%$ power and a type I error rate of 5\% (we included 180 subjects).

In the nested case-control sample matched with respect to analysis time, age in decades, and BMI, relative risk estimates were obtained with use of conditional logistic regression models that in addition to crude models adjusted for several cardiovascular risk factors and medication. In the nested case-control sample, the risk of MI was also calculated by tertiles of MMW/HMW adiponectin. As cases are overrepresented in this case-control study, tertiles were created based on the distribution of MMW/HMW in controls. All P values were two-tailed and values of less than 0.05 were considered to indicate statistical significance. All confidence intervals were calculated at the 95 percentile level. JMP 8 (SAS Institute, Cary, NC) and Stata 8 (StataCorp LP, College Station, TX) were used for statistical analysis. 


\section{Results}

\section{Cross-sectional exploratory study}

The baseline characteristics of the non-diabetic male study participants stratified for obesity and MI are shown in Table 1. Normal-weight control subjects were well comparable with obese control subjects with respect to age, glycosylated hemoglobin, and smoking status. By definition, these two groups differed with respect to BMI, and, though not statistically significant, mean arterial blood pressure, LDL cholesterol, as well as lipid-lowering and blood pressure medication. Baseline characteristics in normal-weight MI patients differed from obese MI patients only with respect to BMI.

The distributions of adiponectin isoforms in the four study groups are depicted in Fig. 1. In subjects without a history of MI, the median proportions of HMW, MMW, and LMW adiponectin isoforms were identical in normal-weight and obese individuals. Analogously, proportions of these isoforms were identical in normal-weight and obese MI patients. However, in both normal-weight and obese MI patients we observed markedly lower proportions of HMW adiponectin and higher proportions of MMW adiponectin than in control subjects.

As expected, in the obese subjects, total adiponectin as well as all multimer forms was significantly lower than in normal-weight subjects (each $p<0.0001$, Supplementary Table 1). These effects could be observed similarly in controls, MI patients, and total study participants.

The median total adiponectin and isoform levels as well as the isoform per total adiponectin ratios in controls and MI patients stratified for obesity are displayed in Table 2 . Total adiponectin levels were almost identical in controls and MI patients, irrespective of being obese $(p=0.34)$ or not $(p=0.75)$. In contrast, HMW levels, particularly HMW/total adiponectin ratios, were lower in MI patients than in controls $(p<0.0001)$. These effects could be observed in normal-weight $(p=0.0008)$ and obese individuals but were more pronounced in obese subjects $(p<0.0001)$. Highly significant differences were also detected for MMW adiponectin levels. MMW levels, particularly related to total adiponectin, were much higher in MI patiens than in controls $(p<0.0001)$. In contrast, LMW adiponectin was similar in controls and MI patients $(p=0.80)$. As the effect sizes of HMW and MMW were in different directions, the strongest differences between MI patients and controls were observed for the MMW/HMW ratio $(p<0.0001)$.

Next, we divided the distribution of MMW/ HMW ratios into tertiles and calculated the proportions of MI patients and controls in these quantiles. The corresponding mosaic plot (cross-tabulation of frequencies of the two categorical variables) is shown in Fig. 2. The proportion of MI patients strongly increased from tertile $1(15 \%)$ to tertile $3(88 \%)$. The chi-square test clearly indicated a strong association between the case-control status and increasing tertiles of MMW/HMW values.

Table 1. Baseline characteristics of study participants stratified for MI and BMI in the exploratory case-control study

\begin{tabular}{|c|c|c|c|c|}
\hline & \multicolumn{2}{|c|}{ Controls } & \multicolumn{2}{|c|}{ MI patients } \\
\hline & Normal-weight & Obese & Normal-weight & Obese \\
\hline$n$ & 45 & 45 & 45 & 45 \\
\hline $\operatorname{Sex}(\% \mathrm{~m})$ & 100 & 100 & 100 & 100 \\
\hline Diabetes (\%) & 0 & 0 & 0 & 0 \\
\hline Age (years) & $50 \pm 10$ & $46 \pm 6$ & $55 \pm 7$ & $58 \pm 9$ \\
\hline $\operatorname{BMI}\left(\mathrm{kg} / \mathrm{m}^{2}\right)$ & $23.2 \pm 1.3$ & $32.3 \pm 2.4$ & $23.7 \pm 1.7$ & $32.2 \pm 2.2$ \\
\hline HbA1c (\%) & $5.2(4.9-5.5)$ & $5.2(4.9-5.5)$ & $5.4(5.1-5.7)$ & $5.4(5.2-5.7)$ \\
\hline MAP (mmHg) & $96 \pm 11$ & $105 \pm 17$ & $97 \pm 11$ & $104 \pm 14$ \\
\hline LDL Chol. (mg/dL) & $140 \pm 45$ & $152 \pm 38$ & $158 \pm 45$ & $163 \pm 42$ \\
\hline HDL Chol. (mg/dL) & $60 \pm 17$ & $46 \pm 14$ & $55 \pm 10$ & $48 \pm 6$ \\
\hline Former Smokers (\%) & 51.1 & 51.1 & 84.4 & 80.0 \\
\hline Smokers (\%) & 46.7 & 35.6 & 15.6 & 6.7 \\
\hline Statins (\%) & 3.6 & 12.5 & 60.0 & 55.6 \\
\hline BP drugs (\%) & 11.1 & 24.4 & 84.4 & 93.3 \\
\hline
\end{tabular}

HbA1c, glycosylated hemoglobin; MAP, mean arterial blood pressure; Chol., cholesterol; BP, blood pressure. Means \pm SD, median (interquartile range), or proportions. 


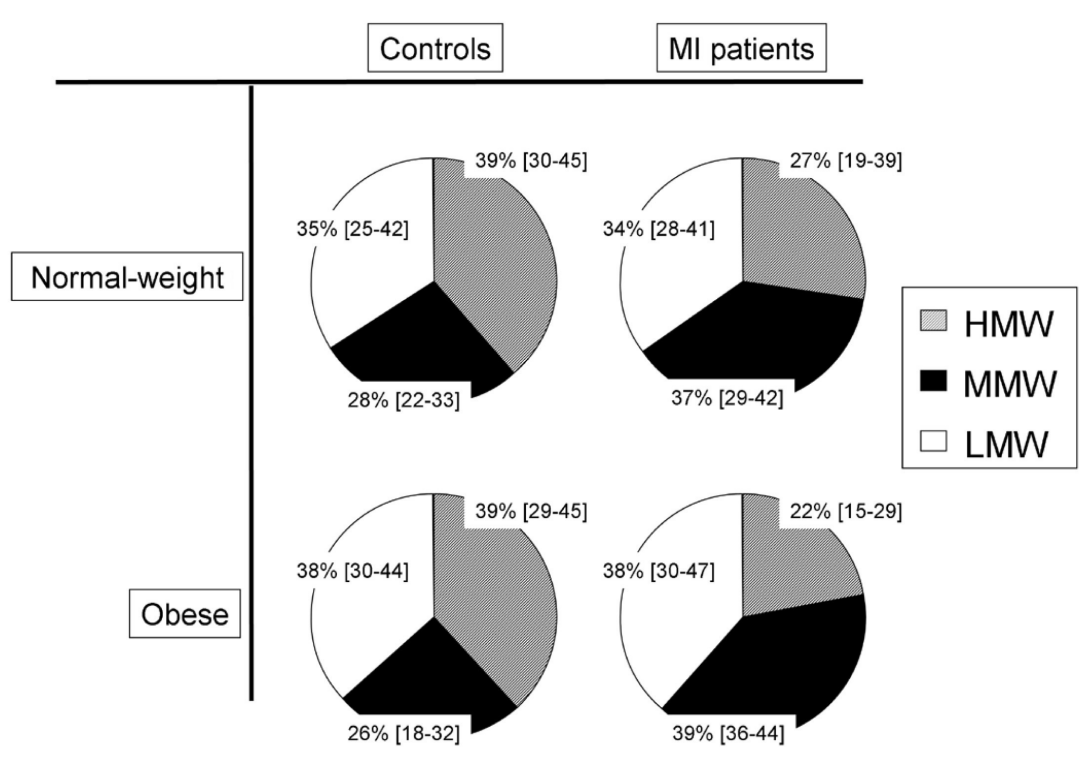

Fig. 1. Distribution of adiponectin isoforms in the four study groups

Medians with interquartile ranges of HMW (high molecular weight oligomeric adiponectin), MMW (middle molecular weight hexameric adiponectin), LMW (low molecular weight trimeric adiponectin) proportions.

Table 2. Total adiponectin and adiponectin isoforms $(\mu \mathrm{g} / \mathrm{mL})$ by MI in all study participants, normal-weight and obese in the exploratory study

\begin{tabular}{|c|c|c|c|c|c|c|c|c|c|}
\hline & \multicolumn{3}{|c|}{ Total } & \multicolumn{3}{|c|}{ Normal-weight } & \multicolumn{3}{|c|}{ Obese } \\
\hline & $\begin{array}{l}\text { Controls } \\
(n=90)\end{array}$ & $\begin{array}{l}\text { MI patients } \\
\quad(n=90)\end{array}$ & $P$ & $\begin{array}{l}\text { Controls } \\
(n=45)\end{array}$ & $\begin{array}{c}\text { MI patients } \\
\quad(n=45)\end{array}$ & $P$ & $\begin{array}{l}\text { Controls } \\
(n=45)\end{array}$ & $\begin{array}{l}\text { MI patients } \\
\quad(n=45)\end{array}$ & $P$ \\
\hline Total & $\begin{array}{c}4.82 \\
(3.54-6.14)\end{array}$ & $\begin{array}{c}4.74 \\
(3.71-6.40)\end{array}$ & 0.718 & $\begin{array}{c}5.54 \\
(4.50-7.97)\end{array}$ & $\begin{array}{c}5.89 \\
(4.25-8.05)\end{array}$ & 0.752 & $\begin{array}{c}4.37 \\
(3.06-5.46)\end{array}$ & $\begin{array}{c}4.07 \\
(2.63-5.06)\end{array}$ & 0.340 \\
\hline HMW & $\begin{array}{c}1.77 \\
(1.27-2.76)\end{array}$ & $\begin{array}{c}1.17 \\
(0.65-2.02)\end{array}$ & 0.0002 & $\begin{array}{c}2.23 \\
(1.52-3.09)\end{array}$ & $\begin{array}{c}1.64 \\
(0.90-2.98)\end{array}$ & 0.117 & $\begin{array}{c}1.60 \\
(0.96-2.24)\end{array}$ & $\begin{array}{c}0.99 \\
(0.44-1.37)\end{array}$ & 0.0002 \\
\hline MMW & $\begin{array}{c}1.21 \\
(0.83-1.66)\end{array}$ & $\begin{array}{c}1.90 \\
(1.30-2.47)\end{array}$ & $<0.0001$ & $\begin{array}{c}1.50 \\
(0.97-2.24)\end{array}$ & $\begin{array}{c}2.09 \\
(1.62-2.64)\end{array}$ & 0.016 & $\begin{array}{c}1.02 \\
(0.78-1.36)\end{array}$ & $\begin{array}{c}1.62 \\
(0.94-2.26)\end{array}$ & $<0.0001$ \\
\hline LMW & $\begin{array}{c}1.64 \\
(1.31-1.98)\end{array}$ & $\begin{array}{c}1.66 \\
(1.23-2.16)\end{array}$ & 0.974 & $\begin{array}{c}1.84 \\
(1.36-2.18)\end{array}$ & $\begin{array}{c}1.86 \\
(1.45-2.49)\end{array}$ & 0.436 & $\begin{array}{c}1.54 \\
(1.26-1.83)\end{array}$ & $\begin{array}{c}1.37 \\
(1.06-1.85)\end{array}$ & 0.396 \\
\hline HMW/Total & $\begin{array}{c}0.39 \\
(0.29-0.45)\end{array}$ & $\begin{array}{c}0.23 \\
(0.19-0.32)\end{array}$ & $<0.0001$ & $\begin{array}{c}0.39 \\
(0.30-0.45)\end{array}$ & $\begin{array}{c}0.27 \\
(0.19-0.39)\end{array}$ & 0.0008 & $\begin{array}{c}0.39 \\
(0.29-0.45)\end{array}$ & $\begin{array}{c}0.22 \\
(0.15-0.29)\end{array}$ & $<0.0001$ \\
\hline MMW/Total & $\begin{array}{c}0.27 \\
(0.21-0.32)\end{array}$ & $\begin{array}{c}0.38 \\
(0.33-0.43)\end{array}$ & $<0.0001$ & $\begin{array}{c}0.28 \\
(0.22-0.33)\end{array}$ & $\begin{array}{c}0.37 \\
(0.29-0.42)\end{array}$ & $<0.0001$ & $\begin{array}{c}0.26 \\
(0.18-0.32)\end{array}$ & $\begin{array}{c}0.38 \\
(0.36-0.44)\end{array}$ & $<0.0001$ \\
\hline LMW/Total & $\begin{array}{c}0.36 \\
(0.29-0.42)\end{array}$ & $\begin{array}{c}0.37 \\
(0.30-0.44)\end{array}$ & 0.796 & $\begin{array}{c}0.34 \\
(0.25-0.42)\end{array}$ & $\begin{array}{c}0.34 \\
(0.28-0.42)\end{array}$ & 0.874 & $\begin{array}{c}0.38 \\
(0.30-0.44)\end{array}$ & $\begin{array}{c}0.38 \\
(0.30-0.47)\end{array}$ & 0.830 \\
\hline MMW/HMW & $\begin{array}{c}0.72 \\
(0.49-1.08)\end{array}$ & $\begin{array}{c}1.71 \\
(1.08-2.40)\end{array}$ & $<0.0001$ & $\begin{array}{c}0.71 \\
(0.54-1.04)\end{array}$ & $\begin{array}{c}1.54 \\
(0.83-2.12)\end{array}$ & $<0.0001$ & $\begin{array}{c}0.72 \\
(0.45-1.16)\end{array}$ & $\begin{array}{c}1.80 \\
(1.27-2.72)\end{array}$ & $<0.0001$ \\
\hline
\end{tabular}

MI, myocardial infarction; Total, total adiponectin; HMW, high molecular weight adiponectin; MMW, middle molecular weight adiponectin; LMW, low molecular weight adiponectin. Median (interquartile range). 
In a multivariate logistic regression model, controlling for several potential confounding factors, the MMW/HMW ratio remained independendly associated with MI (Table 3).

\section{Prospective study}

The baseline characteristics of cases (subjects who experienced fatal or non-fatal MI) and matched controls (subjects who remained free of any cardiovas-

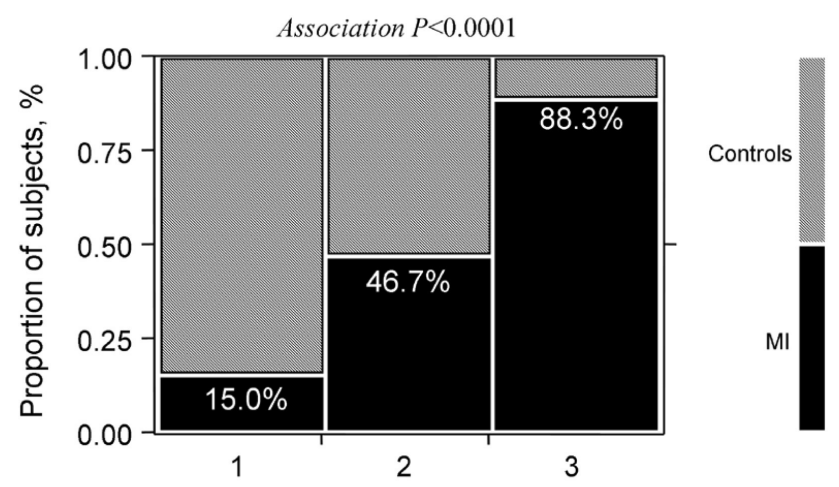

Tertiles of MMW / HMW Ratio

Fig. 2. Mosaic plot (crosstabulation of frequencies of two categorical variables) to illustrate the strong association between increasing tertiles of MMW/HMW levels and MI status

Tertile 1 (MMW/HMW <0.78), Tertile 2 (MMW/HMW $\geq 0.78$ $<1.54)$, Tertile 3 (MMW/HMW $\geq 1.54$ ). cular events until the point of time when the case was diagnosed) are shown in Table 4. Besides the analysis time, cases and controls were matched by age and BMI. The cardiovascular risk factor distribution in these non-diabetic men was pronounced in cases by lower HDL cholesterol levels and slightly higher LDL cholesterol levels.

Interestingly, in this prospective analysis, the MMW/HMW adiponectin ratio was again higher in cases of incident fatal or non-fatal MI than in controls (Fig. 3A) and could be comfirmed to be significantly associated with incident $\mathrm{MI}$ : the relative risk for incident MI almost doubled for subjects in the upper tertile of MMW/HMW ratio distribution compared to subjects in the lower tertile (Fig. 3B). In contrast, neither HMW adiponectin (2.04 (1.02-2.89) vs. 1.93 (1.30-3.30), n.s.) nor MMW adiponectin (1.90 (1.47-2.62) vs. 1.87 (1.32-2.58), n.s.) alone were significantly different in cases and controls, respectively. Likewise, the relative risk for incident MI associated with tertiles of HMW adiponectin did not reach the level of significance.

The MMW/HMW ratio correlated with fatal and non-fatal MI up to 5 years before the event, with ß-estimates decreasing with increasing time to the event (Fig. 4). As in the cross-sectional exploratory study, total adiponectin levels were not associated with incident events in this prospective study $(6.6 \pm 3.0$ (cases) vs. $6.7 \pm 3.2 \mu \mathrm{g} / \mathrm{mL}$ (controls), $p=0.87$ in lo-

Table 3. Multivariate logistic regression model for the association of MI with MMW/HMW adiponectin levels in the exploratory study

\begin{tabular}{lccclc}
\hline Term & Estimate & Std Error & Chi-Square & $P$-value & Odds Ratio (95\% CI) \\
\hline Intercept & 0.959 & 0.410 & 5.46 & 0.019 & - \\
MMW/HMW & 1.243 & 0.357 & 12.10 & 0.0005 & $3.47(1.72-6.98)$ \\
AGE & 0.930 & 0.368 & 6.38 & 0.012 & $2.53(1.23-5.21)$ \\
BMI & 0.030 & 0.332 & 0.01 & 0.929 & $1.03(0.54-1.98)$ \\
MAP & 0.162 & 0.327 & 0.25 & 0.620 & $1.18(0.62-2.23)$ \\
LDL cholesterol & 0.512 & 0.287 & 3.19 & 0.074 & $1.67(0.95-2.93)$ \\
Statins & 1.610 & 0.379 & 18.11 & 0.0001 & $5.00(2.38-10.52)$ \\
HDL cholesterol & -0.218 & 0.359 & 0.37 & 0.543 & $0.80(0.40-1.63)$ \\
Smoking & 0.334 & 0.347 & 0.93 & 0.336 & $1.40(0.71-2.76)$ \\
\hline
\end{tabular}

BMI, body mass index; MAP, mean arterial blood pressure; BP, blood pressure; smoking was former or current smoking. For continuous parameters, odds ratios are unit odds ratios (per unit change in regressor); continuous parameters have been normalized by using an empirical normal quantile transformation for statistical analysis. This allows direct comparisons with respect to the predictive capabilities of the different variables. 
Table 4. Baseline characteristics of cases and controls in the prospective nested case-control study

\begin{tabular}{lccc}
\hline & $\begin{array}{c}\text { Cases } \\
\text { (incident fatal/non-fatal MI) }\end{array}$ & $\begin{array}{c}\text { Controls } \\
\text { (free of any event) }\end{array}$ & P-value \\
\hline$n$ & 56 & 112 & - \\
Sex $(\% \mathrm{M})$ & 100 & 100 & - \\
Diabetes (\%) & 0 & 0 & - \\
Age (years) & $61 \pm 11$ & $59 \pm 12$ & matched \\
BMI (kg/m $\left.{ }^{2}\right)$ & $27.8 \pm 4.3$ & $27.5 \pm 3.7$ & matched \\
Smoker $(\%)$ & 37.5 & 33.0 & 0.568 \\
Former Smoker $(\%)$ & 80.4 & 75.2 & 0.455 \\
MAP (mmHg) & $105 \pm 12$ & $103 \pm 13$ & 0.242 \\
LDL (mg/dL) & $174 \pm 54$ & $161 \pm 39$ & 0.080 \\
HDL (mg/dL) & $49 \pm 12$ & $53 \pm 14$ & 0.051 \\
HbAlc $(\%)$ & $5.5(5.2-5.8)$ & $5.4(5.1-5.7)$ & 0.169 \\
BP Drugs $(\%)$ & 41.1 & 33.9 & 0.367 \\
Statins $(\%)$ & 7.1 & 10.1 & 0.533 \\
\hline
\end{tabular}

MAP, mean arterial blood pressure; LDL, LDL cholesterol; HDL, HDL cholesterol; HbA1c, glycosylated hemoglobin; BP, blood pressure. Means $\pm \mathrm{SD}$, median (interquartile range), or proportions.
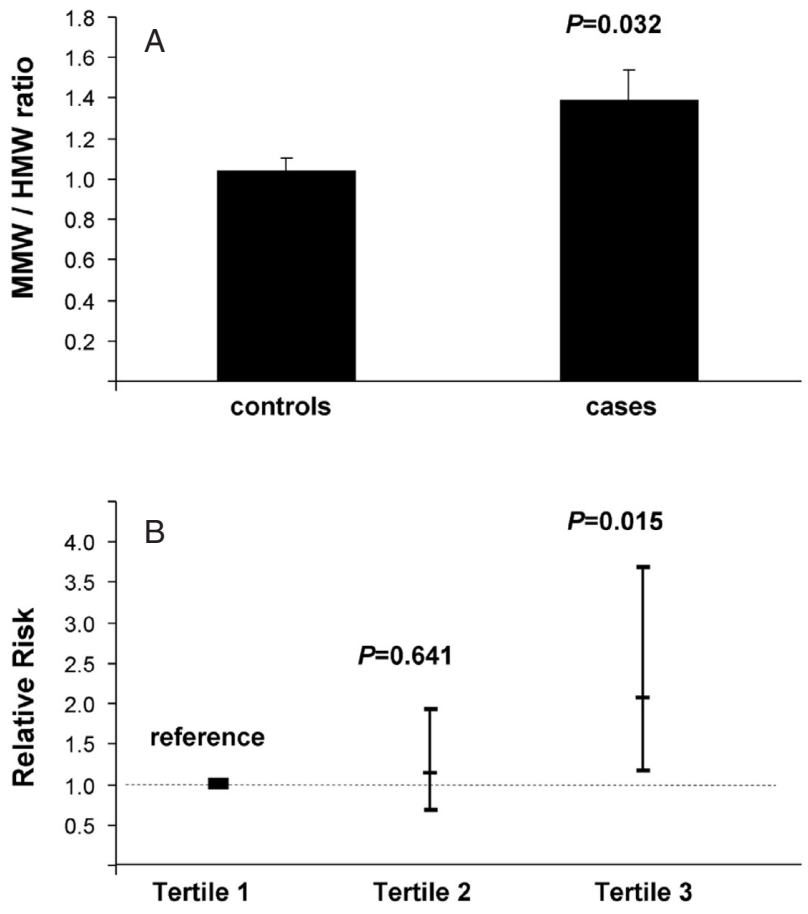

Fig.3.

A: MMW/HMW levels in cases of incident fatal or non-fatal MI $(n=56)$ and controls $(n=112)$ who remained free of any cardiovascular event in the prospective nested case control study. B: Relative risk of incident fatal or non-fatal MI by increasing tertiles of MMW/HMW levels in initially healthy non-diabetic men. Tertile 1 (MMW/HMW <0.78) Tertile 2 (MMW/HMW $\geq 0.78-<$ 1.54 ,), Tertile 3 (MMW/HMW $\geq 1.54$ ). The proportion of cases increased from $29 \%$ (Tertile 1) to $50 \%$ (Tertile 3).

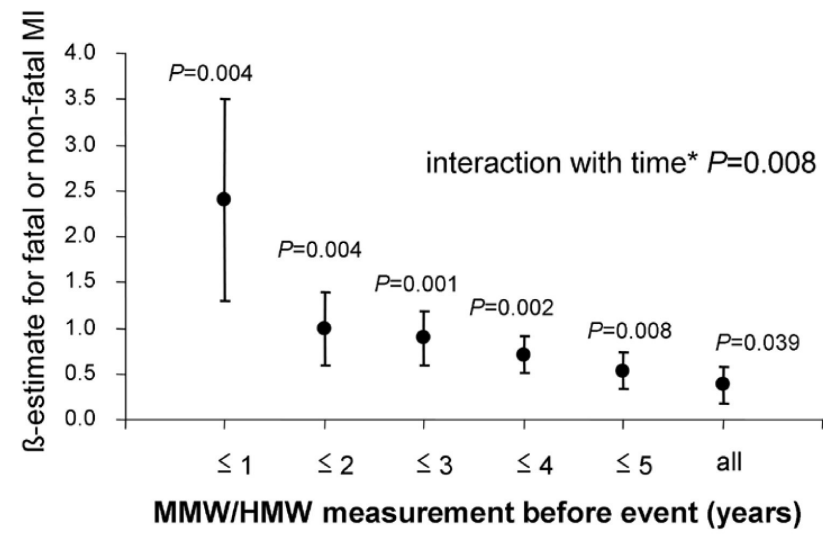

Fig.4. B-estimates for incident fatal or non-fatal MI according to the time between adiponectin measurement (baseline examination) and the occurrence of the event

The B-estimates decrease by the length of follow-up, i.e. by the time between the adiponectin measurement and the incident event. $<1$ year $(n=24),<2$ years $(\mathrm{n}=63),<3$ years $(n=81),<4$ years $(n=105),<5$ years $(n=132)$, all $(n=168) . *$ time as a continuous variable.

gistic regression analysis accounting for time to the event).

\section{Discussion}

The present study was designed to examine the relationship of adiponectin multimers with $\mathrm{MI}$ in obese and normal-weight non-diabetic men with a positive family history of MI. We observed that 1) total adiponectin levels were not associated with $\mathrm{MI}$ in 
non-diabetic men in obese or non-obese subjects, and 2) MMW and HMW adiponectin levels were correlated with a differential pattern (HMW inversely) with MI in both obese and non-obese men. Since the correlation between MI and both isoforms tends to head in different directions, the MMW/HMW ratio was strongly associated with MI. Notably, we comfirmed the association of the MMW/HMW ratio with incident MI in our prospective nested case-control study.

Since its discovery, adiponectin has been the center of intense debate regarding its prognostic significance for CAD in different primary and secondary prevention settings. This is partly due to the apparent paradox between experimental data, suggesting a protective effect on the vasculature, and epidemiological evidence failing to confirm this effect and even suggesting an increased risk in certain patient groups. However, as it is now possible to measure adiponectin multimers accurately, the biological importance of each one of these isoforms may be scrutinized with the potential to resolve the paradox ${ }^{2)}$.

Adiponectin circulates in plasma in three forms: a trimer (low molecular weight), a trimer-dimer of medium molecular weight, and a larger multimeric high molecular weight (HMW) form ${ }^{6,27-29)}$. Previous measurement of HMW, which was suggested to be the most active form, was laborious and time-consuming and inappropriate for assessment in larger sample size studies. Epidemiological evidence of an association between adiponectin isoforms and cardiovascular disease is thus scarce, and so far is mainly based on the HMW isoform and total adiponectin levels, and is supported by studies of small sample sizes conducted in CAD patients. These few studies of small sample size conducted in CAD patients suggest an inverse association between the HMW adiponectin isoform and CAD in accordance with experimental evidence; however, data are conflicting. Notably, in a recent longitudinal study including more than 1000 CAD patients, neither HMW adiponectin nor total adiponectin predicted recurrent cardiovascular events, and they were also not associated with mortality ${ }^{43}$. However, this study also had some limitations, such as the measurement of adiponectins after a 3-week cardiac rehabilitation program, a period during which patients had been advised to change their lifestyle, lose weight, and had received drugs for the management of their global cardiovascular risk. These changes likely influenced adiponectin levels and/or individual isoform proportions. Next, MMW and LMW oligomers were not measured in this study as in others, and thus, there was still a need to quantify the contribution of adiponectin iso- forms to coronary disease risk.

Our study adds new data regarding the role of adiponectin isoforms in MI in two different settings by investigating the isoforms in non-diabetic male MI patients and controls cross-sectionally, and moreover, by studying initially healthy male subjects for incident MI. In both settings, with the atherosclerotic disease process probably being at different stages, we observed that HMW and MMW, but not LMW isoforms might be relevant, independently of being obese or not. In the prospective study we observed a decreasing association of the MMW/HMW ratio with coronary risk over time. This could be due to the fact that the pathophysiological role of adiponectin is not only related to the atherosclerotic burden, but also to the stability and composition of atherosclerotic plaque ${ }^{44)}$ as well as to platelet activation ${ }^{45}$, suggesting a role of the adiponectins in the pathogenesis of both atherosclerosis and acute coronary syndromes.

Data supporting the biological significance of MMW hexamers are scarce. Most studies correlating adiponectins with parameters of body fat or metabolic syndrome did not investigate MMW or found only marginal effects.

MMW adiponectin may have pro-inflammatory properties in vitro - exposure of monocytes to MMW adiponectin results in increased secretion of IL-6 in IL-8 chemokines ${ }^{46,47)}$, and both isoforms (but not LMW trimers) activate the NF-kappaB signaling pathway ${ }^{48,}{ }^{49}$. HMW but not MMW or LMW isoforms protects endothelial cells against apoptosis ${ }^{34)}$. Thus, adiponectin may have important regulatory effects on the integrity of the vasculature system by its intravascular pro-inflammatory response, endothelial cell dysfunction and the changes in adiponectin isoforms.

Interestingly, an increased proportion of MMW and a decreased proportion of HMW isoform levels (like in our MI patients) could also be observed in patients with preeclampsia ${ }^{50)}$, which is characterized by an exaggerated intravascular proinflammatory response as well as by endothelial cell dysfunction ${ }^{50)}$. Moreover, in a small randomized controlled study by Von Eynatten et al., 8-week treatment with $40 \mathrm{mg}$ atorvastatin but not a placebo reduced MMW by $21 \%$ and increased HMW by $42 \%{ }^{51)}$. In contrast, no effect could be observed in total adiponectin levels, suggesting that statins exert a marked decrease in the MMW/ HMW ratio, which might also support our findings.

It should be mentioned that our study population consisted of subjects with a strong family history of MI. A selection bias might exist in that our sample was selected via index cases of MI before 60 years of 
age. As a result, common real-world MI cases might be underrepresented in our study sample. Moreover, it may be that MI cases and their siblings have received preventive messages regarding their cardiovascular risk. Thus, another form of selection bias might exist in that our initial healthy siblings of MI patients potentially seek medical help more quickly when a family member experiences an MI. Moreover, we cannot exclude that "control subjects" did not have subclinical CAD; therefore, our results might not be generalizable to other populations. Also, our results might not be generalizable to women and subjects with diabetes as we restriced our investigation to non-diabetic men. Moreover, the effect of adiponectins may not be independent but rather due to a clustering of plasma adiponectin levels with several other variables, such as overall risk profile, medical history, lifestyle, and concurrent medical treatment, which might all interact with plasma adiponectin levels in determining the outcome. We studied changes in risk factors and medications during follow-up (data not shown); however, no apparent shifting in risk factors or newly started drugs may explain the association between MMW/ HMW and incident events. As fasting glucose levels were not measured in our study population, type 2 diabetes was defined as a positive history of diabetes, use of antidiabetic drugs or insulin, and/or a HbA1C $\geq$ $6.5 \%$. Thus, it is possible that a minority of subjects with prediabetes or diabetes were unrecognized and incorrectly classified as "non-diabetic". We also had no information about the degree of left ventricular dysfunction after previous MI in our cross-sectional study. This could also slightly influence adiponectin levels in the present study. Thus, our small sample size suggests that the role of the different adiponectin isoforms needs to be further determined. The same applies to the need to define the biological mechanisms that confer the observed effects. Finally, storage conditions of blood samples (e.g. storage time and temperature) may be suggested to alter adiponectin levels; however, we compared adiponectin concentrations in serum aliquots stored for 3 and 36 months at $-80^{\circ} \mathrm{C}$. Adiponectin levels were not significantly different, suggesting that storage conditions did not impact on our results due to adequate specimen stability, which was also confirmed by those who developed the methods.

In summary, we showed that total adiponectin and all isoforms were related to obesity, but total adiponectin and LMW trimer levels were not associated with MI in non-diabetic men. In contrast, the MMW/ HMW adiponectin ratio was strongly associated with MI cross-sectionally and with incident MI up to 5 years before the event.

Our data imply that measurement of adiponectin multimers adds significant value in assessing cardiovascular risk compared to total adiponectin alone.

\section{Acknowledgments}

This work was supported by the Deutsche Akademie für Naturforscher Leopoldina and grants from the Bundesministerium für Bildung und Forschung (BMBF-LPD 9901/8-72), the Deutsche Forschungsgemeinschaft (Schu672/10-1, Schu672/12-1, Schu672/ 14-1, He1921/9-1, and BA2227/1-1), the Federal Ministry for Research (KBF-FKZ 01GB9403), the Deutsche Forschungsgemeinschaft and the German Federal Ministry of Education and Research $(\mathrm{BMBF})$ in the context of the German National Genome Research Network (NGFN-2 and NGFN-plus), the Deutsche Stiftung für Herzforschung, Germany, and the European integrated project "Cardiogenics" (LSHM-CT-2006-037593).

\section{References}

1) Hug C, Lodish HF: The role of the adipocyte hormone adiponectin in cardiovascular disease. Curr Opin Pharmacol, 2005; 5: 129-134

2) Kadowaki T, Yamauchi T, Kubota N, Hara K, Ueki K, Tobe K: Adiponectin and adiponectin receptors in insulin resistance, diabetes, and the metabolic syndrome. J Clin Invest, 2006; 116: 1784-1792

3) Scherer PE: Adipose tissue: from lipid storage compartment to endocrine organ. Diabetes, 2006; 55: 1537-1545

4) Khalili P, Flyvbjerg A, Frystyk J, Lundin F, Jendle J, Engstrom G, Nilsson PM: Total adiponectin does not predict cardiovascular events in middle-aged men in a prospective, long-term follow-up study. Diabetes Metab, 2010; 36: $137-143$

5) Ouchi N, Shibata R, Walsh K: Cardioprotection by adiponectin. Trends Cardiovasc Med, 2006; 16: 141-146

6) Giannessi D, Maltinti M, Del Ry S: Adiponectin circulating levels: a new emerging biomarker of cardiovascular risk. Pharmacol Res, 2007; 56: 459-467

7) Kumada M, Kihara S, Sumitsuji S, Kawamoto T, Matsumoto S, Ouchi N, Arita Y, Okamoto Y, Shimomura I, Hiraoka H, Nakamura T, Funahashi T, Matsuzawa Y: Association of hypoadiponectinemia with coronary artery disease in men. Arterioscler Thromb Vasc Biol, 2003; 23: 85-89

8) Otsuka F, Sugiyama S, Kojima S, Maruyoshi H, Funahashi T, Matsui K, Sakamoto T, Yoshimura M, Kimura K, Umemura S, Ogawa H: Plasma adiponectin levels are associated with coronary lesion complexity in men with coronary artery disease. J Am Coll Cardiol, 2006; 48: $1155-1162$

9) Ouchi N, Kihara S, Arita Y, Maeda K, Kuriyama H, Oka- 
moto Y, Hotta K, Nishida M, Takahashi M, Nakamura T, Yamashita S, Funahashi T, Matsuzawa Y: Novel modulator for endothelial adhesion molecules: adipocyte-derived plasma protein adiponectin. Circulation, 1999; 100: 24732476

10) Pischon T, Girman CJ, Hotamisligil GS, Rifai N, Hu FB, Rimm EB: Plasma adiponectin levels and risk of myocardial infarction in men. JAMA, 2004; 291: 1730- 1737

11) Frystyk J, Berne C, Berglund L, Jensevik K, Flyvbjerg A, Zethelius B: Serum adiponectin is a predictor of coronary heart disease: a population-based 10-year follow-up study in elderly men. J Clin Endocrinol Metab, 2007; 92: 571576

12) Huang SS, Huang PH, Chen YH, Chiang KH, Chen JW, Lin SJ: Association of adiponectin with future cardiovascular events in patients after acute myocardial infarction. J Atheroscler Thromb, 2010; 17: 295-303

13) Lim S, Koo BK, Cho SW, Kihara S, Funahashi T, Cho YM, Kim SY, Lee HK, Shimomura I, Park KS: Association of adiponectin and resistin with cardiovascular events in Korean patients with type 2 diabetes: the Korean atherosclerosis study (KAS): a 42-month prospective study. Atherosclerosis, 2008; 196: 398-404

14) Schnabel R, Messow CM, Lubos E, Espinola-Klein C, Rupprecht HJ, Bickel C, Sinning C, Tzikas S, Keller T, Genth-Zotz S, Lackner KJ, Munzel TF, Blankenberg S: Association of adiponectin with adverse outcome in coronary artery disease patients: results from the AtheroGene study. Eur Heart J, 2008; 29: 649-657

15) Cavusoglu E, Ruwende C, Chopra V, Yanamadala S, Eng C, Clark LT, Pinsky DJ, Marmur JD: Adiponectin is an independent predictor of all-cause mortality, cardiac mortality, and myocardial infarction in patients presenting with chest pain. Eur Heart J, 2006; 27: 2300-2309

16) Pilz S, Maerz W, Weihrauch G, Sargsyan K, Almer G, Nauck M, Boehm BO, Winkelmann BR, Mangge H: Adiponectin serum concentrations in men with coronary artery disease: the LUdwigshafen RIsk and Cardiovascular Health (LURIC) study. Clin Chim Acta, 2006; 364: 251255

17) Dekker JM, Funahashi T, Nijpels G, Pilz S, Stehouwer CD, Snijder MB, Bouter LM, Matsuzawa Y, Shimomura I, Heine RJ: Prognostic value of adiponectin for cardiovascular disease and mortality. J Clin Endocrinol Metab, 2008; 93: 1489-1496

18) Hatano Y, Matsumoto M, Ishikawa S, Kajii E: Plasma adiponectin level and myocardial infarction: the JMS Cohort Study. J Epidemiol, 2009; 19: 49-55

19) Laughlin GA, Barrett-Connor E, May S, Langenberg C: Association of adiponectin with coronary heart disease and mortality: the Rancho Bernardo study. Am J Epidemiol, 2007; 165: 164-174

20) Lawlor DA, Davey Smith G, Ebrahim S, Thompson C, Sattar N: Plasma adiponectin levels are associated with insulin resistance, but do not predict future risk of coronary heart disease in women. J Clin Endocrinol Metab, 2005; 90: $5677-5683$

21) Lindsay RS, Resnick HE, Zhu J, Tun ML, Howard BV, Zhang Y, Yeh J, Best LG: Adiponectin and coronary heart disease: the Strong Heart Study. Arterioscler Thromb Vasc
Biol, 2005; 25: e15-e16

22) Sattar N, Wannamethee G, Sarwar N, Tchernova J, Cherry L, Wallace AM, Danesh J, Whincup PH: Adiponectin and coronary heart disease: a prospective study and metaanalysis. Circulation, 2006; 114: 623-629

23) Bottner A, Kratzsch J, Muller G, Kapellen TM, Bluher S, Keller E, Bluher M, Kiess W: Gender differences of adiponectin levels develop during the progression of puberty and are related to serum androgen levels. J Clin Endocrinol Metab, 2004; 89: 4053-4061

24) Combs TP, Berg AH, Rajala MW, Klebanov S, Iyengar P, Jimenez-Chillaron JC, Patti ME, Klein SL, Weinstein RS, Scherer PE: Sexual differentiation, pregnancy, calorie restriction, and aging affect the adipocyte-specific secretory protein adiponectin. Diabetes, 2003; 52: 268-276

25) Galvan RE, Basurto L, Saucedo R, Campos S, Hernandez M, Zarate A: Adiponectin concentrations during menstrual cycle. Ginecol Obstet Mex, 2007; 75: 435-438

26) Mojiminiyi OA, Abdella NA, Al Arouj M, Ben Nakhi A: Adiponectin, insulin resistance and clinical expression of the metabolic syndrome in patients with Type 2 diabetes. Int J Obes (Lond), 2007; 31: 213-220

27) Pajvani UB, Hawkins M, Combs TP, Rajala MW, Doebber T, Berger JP, Wagner JA, Wu M, Knopps A, Xiang AH, Utzschneider KM, Kahn SE, Olefsky JM, Buchanan TA, Scherer PE: Complex distribution, not absolute amount of adiponectin, correlates with thiazolidinedionemediated improvement in insulin sensitivity. J Biol Chem, 2004; 279: 12152-12162

28) Empana JP: Adiponectin isoforms and cardiovascular disease: the epidemiological evidence has just begun. Eur Heart J, 2008; 29: 1221-1223

29) Whitehead JP, Richards AA, Hickman IJ, Macdonald GA, Prins JB: Adiponectin--a key adipokine in the metabolic syndrome. Diabetes Obes Metab, 2006; 8: 264-280

30) Araki S, Dobashi K, Kubo K, Asayama K, Shirahata A: High molecular weight, rather than total, adiponectin levels better reflect metabolic abnormalities associated with childhood obesity. J Clin Endocrinol Metab, 2006; 91: 5113-5116

31) Aso Y, Yamamoto R, Wakabayashi S, Uchida T, Takayanagi K, Takebayashi K, Okuno T, Inoue T, Node K, Tobe T, Inukai T, Nakano Y: Comparison of serum high-molecular weight (HMW) adiponectin with total adiponectin concentrations in type 2 diabetic patients with coronary artery disease using a novel enzyme-linked immunosorbent assay to detect HMW adiponectin. Diabetes, 2006; 55: 1954-1960

32) Inoue T, Kotooka N, Morooka T, Komoda H, Uchida T, Aso Y, Inukai T, Okuno T, Node K: High molecular weight adiponectin as a predictor of long-term clinical outcome in patients with coronary artery disease. Am J Cardiol, 2007; 100: 569-574

33) Liang KW, Lee WJ, Lee WL, Ting CT, Sheu WH: Decreased ratio of high-molecular-weight to total adiponectin is associated with angiographic coronary atherosclerosis severity but not restenosis. Clin Chim Acta, 2009; 405: 114-118

34) Kobayashi H, Ouchi N, Kihara S, Walsh K, Kumada M, Abe Y, Funahashi T, Matsuzawa Y: Selective suppression 
of endothelial cell apoptosis by the high molecular weight form of adiponectin. Circ Res, 2004; 94: e27-e31

35) Teoh H, Strauss MH, Szmitko PE, Verma S: Adiponectin and myocardial infarction: A paradox or a paradigm? Eur Heart J, 2006; 27: 2266-2268

36) Tonelli J, Li W, Kishore P, Pajvani UB, Kwon E, Weaver C, Scherer PE, Hawkins M: Mechanisms of early insulinsensitizing effects of thiazolidinediones in type 2 diabetes. Diabetes, 2004; 53 :1621-1629

37) Rizza S, Clementi F, Porzio O, Cardellini M, Savo A, Serino M, Chiricolo G, Romeo F, Lauro R, Federici M: Adiponectin isoforms are not associated with the severity of coronary atherosclerosis but with undiagnosed diabetes in patients affected by stable CAD. Nutr Metab Cardiovasc Dis, 2009; 19: 54-60

38) Broeckel U, Hengstenberg C, Mayer B, Holmer S, Martin LJ, Comuzzie AG, Blangero J, Nurnberg P, Reis A, Riegger GA, Jacob HJ, Schunkert H: A comprehensive linkage analysis for myocardial infarction and its related risk factors. Nat Genet, 2002; 30: 210-214

39) Fischer M, Broeckel U, Holmer S, Baessler A, Hengstenberg C, Mayer B, Erdmann J, Klein G, Riegger G, Jacob HJ, Schunkert H: Distinct heritable patterns of angiographic coronary artery disease in families with myocardial infarction. Circulation, 2005; 111: 855-862

40) Samani NJ, Erdmann J, Hall AS, Hengstenberg C, Mangino M, Mayer B, Dixon RJ, Meitinger T, Braund P, Wichmann HE, Barrett JH, Konig IR, Stevens SE, Szymczak S, Tregouet DA, Iles MM, Pahlke F, Pollard H, Lieb W, Cambien F, Fischer M, Ouwehand W, Blankenberg S, Balmforth AJ, Baessler A, Ball SG, Strom TM, Braenne I, Gieger C, Deloukas P, Tobin MD, Ziegler A, Thompson JR, Schunkert H: Genomewide association analysis of coronary artery disease. N Engl J Med, 2007; 357: 443-453

41) Koshimura J, Fujita H, Narita T, Shimotomai T, Hosoba M, Yoshioka N, Kakei M, Fujishima H, Ito S: Urinary adiponectin excretion is increased in patients with overt diabetic nephropathy. Biochem Biophys Res Commun, 2004; 316: 165-169

42) Peng B, Yu RK, Dehoff KL, Amos CI: Normalizing a large number of quantitative traits using empirical normal quantile transformation. BMC Proc, 2007; 1 Suppl 1: S156

43) von Eynatten M, Hamann A, Twardella D, Nawroth PP,
Brenner H, Rothenbacher D: Atherogenic dyslipidaemia but not total- and high-molecular weight adiponectin are associated with the prognostic outcome in patients with coronary heart disease. Eur Heart J, 2008; 29: 1307-1315

44) Broedl UC, Lebherz C, Lehrke M, Stark R, Greif M, Becker A, von Ziegler F, Tittus J, Reiser M, Becker C, Goke B, Parhofer KG, Leber AW: Low adiponectin levels are an independent predictor of mixed and non-calcified coronary atherosclerotic plaques. PLoS One, 2009; 4: e4733.

45) Bigalke B, Stellos K, Geisler T, Seizer P, Mozes V, Gawaz M: High plasma levels of adipocytokines are associated with platelet activation in patients with coronary artery disease. Platelets, 2010; 21: 11-19

46) Abke S, Neumeier M, Weigert J, Wehrwein G, Eggenhofer E, Schaffler A, Maier K, Aslanidis C, Scholmerich J, Buechler C: Adiponectin-induced secretion of interleukin-6 (IL-6), monocyte chemotactic protein-1 (MCP-1, CCL2) and interleukin-8 (IL-8, CXCL8) is impaired in monocytes from patients with type I diabetes. Cardiovasc Diabetol, 2006; 5: 17

47) Rovin BH, Song H: Chemokine induction by the adipocyte-derived cytokine adiponectin. Clin Immunol, 2006; 120: 99-105

48) Haugen F, Drevon CA: Activation of nuclear factor-kap$\mathrm{paB}$ by high molecular weight and globular adiponectin. Endocrinology, 2007; 148: 5478-5486.

49) Tsao TS, Tomas E, Murrey HE, Hug C, Lee DH, Ruderman NB, Heuser JE, Lodish HF: Role of disulfide bonds in Acrp30/adiponectin structure and signaling specificity. Different oligomers activate different signal transduction pathways. J Biol Chem, 2003; 278: 50810-50817

50) Mazaki-Tovi S, Romero R, Vaisbuch E, Kusanovic JP, Erez O, Gotsch F, Chaiworapongsa T, Than NG, Kim SK, Nhan-Chang CL, Jodicke C, Pacora P, Yeo L, Dong Z, Yoon BH, Hassan SS, Mittal P: Maternal serum adiponectin multimers in preeclampsia. J Perinat Med, 2009; 37: 623-625

51) von Eynatten M, Liu D, Bluemm A, Schuster T, Baumann M, Lutz J, Heemann U, Dugi K, Nawroth P, Bierhaus A, Humpert P: Changes in adiponectin multimer distribution in response to atorvastatin treatment in patients with type 2 diabetes. Clin Endocrinol, 2008; 71: 27-32. 
Supplemental Table 1. Total adiponectin and adiponectin isoforms $(\mu \mathrm{g} / \mathrm{mL})$ by obesity in all study participants, controls and MI patients in the exploratory study

\begin{tabular}{|c|c|c|c|c|c|c|c|c|c|}
\hline & \multicolumn{3}{|l|}{ Total } & \multicolumn{3}{|l|}{ Controls } & \multicolumn{3}{|l|}{ MI patients } \\
\hline & $\begin{array}{l}\text { Normal-weight } \\
\quad(n=90)\end{array}$ & $\begin{array}{l}\text { Obese } \\
(n=90)\end{array}$ & $P$ & $\begin{array}{l}\text { Normal-weight } \\
\quad(n=45)\end{array}$ & $\begin{array}{l}\text { Obese } \\
(n=45)\end{array}$ & $P$ & $\begin{array}{l}\text { Normal-weight } \\
\quad(n=45)\end{array}$ & $\begin{array}{l}\text { Obese } \\
(n=45)\end{array}$ & $P$ \\
\hline Total & $\begin{array}{c}5.66 \\
(4.31-7.36)\end{array}$ & $\begin{array}{c}4.14 \\
(3.02-5.27)\end{array}$ & $<0.0001$ & $\begin{array}{c}5.54 \\
(4.50-7.07)\end{array}$ & $\begin{array}{c}4.37 \\
(3.06-5.46)\end{array}$ & 0.003 & $\begin{array}{c}5.89 \\
(4.25-8.05)\end{array}$ & $\begin{array}{c}4.07 \\
(2.63-5.06)\end{array}$ & 0.0001 \\
\hline HMW & $\begin{array}{c}1.77 \\
(1.08-3.02)\end{array}$ & $\begin{array}{c}1.27 \\
(0.61-1.88)\end{array}$ & $<0.0001$ & $\begin{array}{c}2.23 \\
(1.52-3.09)\end{array}$ & $\begin{array}{c}1.60 \\
(0.96-2.24)\end{array}$ & 0.018 & $\begin{array}{c}1.64 \\
(0.90-2.98)\end{array}$ & $\begin{array}{c}0.99 \\
(0.44-1.37)\end{array}$ & 0.0001 \\
\hline MMW & $\begin{array}{c}1.92 \\
(1.27-2.52)\end{array}$ & $\begin{array}{c}1.24 \\
(0.85-1.79)\end{array}$ & $<0.0001$ & $\begin{array}{c}1.50 \\
(0.97-2.24)\end{array}$ & $\begin{array}{c}1.02 \\
(0.78-1.36)\end{array}$ & 0.0004 & $\begin{array}{c}2.09 \\
(1.62-2.64)\end{array}$ & $\begin{array}{c}1.62 \\
(0.94-2.26)\end{array}$ & 0.023 \\
\hline LMW & $\begin{array}{c}1.85 \\
(1.40-2.32)\end{array}$ & $\begin{array}{c}1.45 \\
(1.17-1.83)\end{array}$ & 0.0001 & $\begin{array}{c}1.84 \\
(1.36-2.18)\end{array}$ & $\begin{array}{c}1.54 \\
(1.26-1.83)\end{array}$ & 0.083 & $\begin{array}{c}1.86 \\
(1.45-2.49)\end{array}$ & $\begin{array}{c}1.37 \\
(1.06-1.85)\end{array}$ & 0.001 \\
\hline HMW/Total & $\begin{array}{c}0.34 \\
(0.23-0.43)\end{array}$ & $\begin{array}{c}0.29 \\
(0.20-0.40)\end{array}$ & 0.027 & $\begin{array}{c}0.39 \\
(0.30-0.45)\end{array}$ & $\begin{array}{c}0.39 \\
(0.29-0.45)\end{array}$ & 0.599 & $\begin{array}{c}0.27 \\
(0.19-0.39)\end{array}$ & $\begin{array}{c}0.22 \\
(0.15-0.29)\end{array}$ & 0.004 \\
\hline MMW/Total & $\begin{array}{c}0.30 \\
(0.25-0.40)\end{array}$ & $\begin{array}{c}0.34 \\
(0.25-0.40)\end{array}$ & 0.570 & $\begin{array}{c}0.28 \\
(0.22-0.33)\end{array}$ & $\begin{array}{c}0.26 \\
(0.18-0.32)\end{array}$ & 0.237 & $\begin{array}{c}0.37 \\
(0.29-0.42)\end{array}$ & $\begin{array}{c}0.38 \\
(0.36-0.44)\end{array}$ & 0.025 \\
\hline LMW/Total & $\begin{array}{c}0.34 \\
(0.27-0.42)\end{array}$ & $\begin{array}{c}0.38 \\
(0.30-0.46)\end{array}$ & 0.034 & $\begin{array}{c}0.34 \\
(0.25-0.42)\end{array}$ & $\begin{array}{c}0.38 \\
(0.30-0.44)\end{array}$ & 0.152 & $\begin{array}{c}0.34 \\
(0.28-0.41)\end{array}$ & $\begin{array}{c}0.38 \\
(0.30-0.47)\end{array}$ & 0.119 \\
\hline MMW/HMW & $\begin{array}{c}0.87 \\
(0.67-1.64)\end{array}$ & $\begin{array}{c}1.25 \\
(0.72-1.87)\end{array}$ & 0.080 & $\begin{array}{c}0.71 \\
(0.54-1.04)\end{array}$ & $\begin{array}{c}0.72 \\
(0.45-1.16)\end{array}$ & 0.812 & $\begin{array}{c}1.53 \\
(0.83-2.12)\end{array}$ & $\begin{array}{c}1.80 \\
(1.27-2.72)\end{array}$ & 0.002 \\
\hline
\end{tabular}

MI, myocardial infarction; Total, total adiponectin; HMW, high molecular weight adiponectin; MMW, middle molecular weight adiponectin; LMW, low molecular weight adiponectin. Median (interquartile range). 